\title{
Introduction: \\ The city without qualities
}

\author{
Hannah Hopewell \& Andrew Douglas
}

\begin{abstract}
If all those leaps of attention, flexing of eye muscles, fluctuations of the psyche, if all the effort it takes for a man just to hold himself upright within the flow of traffic on a busy street could be measured, he thought - as he toyed with calculating the incalculable - the grand total would surely dwarf the energy needed by Atlas to hold up the world, and one could then estimate the enormous undertaking it is nowadays merely to be a person who does nothing at all. At the moment, the man without qualities was just such a person.
\end{abstract}

Robert Musil, The man without qualities (1930-43)

Writing in the age of the metropolis and the great urban concentration spawned by industrialisation and imperial expansion, Musil sketched a scene of super-saturated, sensory life in which, beyond any personal purview, "A world of qualities without a man has arisen", a world in which private experience, indeed personal experience tout court, dissolves into a systematised grab for human attention run to the limit (Musil 1996: 158159). In the intervening three quarters of a century the urban itself has assumed in many instances a ubiquity worthy of the title, the city without qualities. If one consequence of the truncation of human agency Musil figured he was seeing in people as "passionate and detached at the same time" was a calculatedly implanted will to irresponsibility attending an exhausting immersion in spectacle (Musil 1996: 159), another is a macroscaled collapse of civil responsibility and civility once upheld by the term urbanity. For Jean-Luc Nancy, while 'the city' spreads to envelope "the orb of the world", it displaces the old "religious Christian bond" found in the west - expressed through the papal benediction addressed to the urbi et orbi (to the city and the world) - instituting instead an "agglomeration" or piling up that crowds out the possibility of the civility and hospitality once aspired to in a city-world conjoining. In place of well-being, he suggests, urban conglomeration ushers in a quality that more commonly "bears the quite simple and unmerciful name of misery" (33).

In establishing the theme for this issue of Interstices, it is this uncertain dichotomy in the urban between wellbeing and misery - a dichotomy seemingly linked to its expanding, de-formation as figure - that we aimed would be teased out and tested. As Lewis Mumford long ago claimed, the idea of the urban itself is linked to a protean impulse - to live a civic life, one where accumulating abundance might lead to social enjoyment and symbolic richness beyond mere subsistence. In short, the urban has, and ought to still, enlarge, as Mumford reflects through Aristotle, "the good life in embryo" (16). Yet despite contemporaniety's manifest loss of such collective largesse, it warrants seeing in the urban the virtual equipment for the 'eruption' of broadly effected agency and enrichment.

In this regard, the sheer volume of discourses on the urban point to both deep cultural anxieties about the worth, utility, or even sense of cities and their persisting, emancipatory appeal. Yet the plethora of claims on the value and sustained identity of urban place potentially operates as cover for something far more disconcerting - something that Saskia Sassen calls the savage sorting effected by cities (a sorting out of the trustworthy from the suspicious, the haves from the have-nots, and the new productive and cultural elites from the rest). Further, if we follow Arjun Appendurai for instance, cities are both antithetical to national territoriality and are incubators for working out the tumult of citizenship against a backdrop of highly contested, sometimes violently contested, identity claims. Yet if cities test citizenry difference and work through what gets popularly instituted and affectively consolidated at a national-territorial level, they are themselves at the front line of a contestatory political-economic regime channelled through governance mechanisms.

In a recent essay in the Guardian, Sassen for example, sees (in the context of a buy up of urban land by corporate interests) city-ness itself being 
subjected to a radical remaking. As complex places where, as she said, "those without power [also] get to make a history and a culture", cities have long harboured a cosmopolitanism in excess of prevailing socio-economic and governmental force. It is their longevity and sheer persistence that gives cities an open, emancipatory edge:

A city is a complex but incomplete system: in this mix lies the capacity of cities across histories and geographies to outlive far more powerful, but fully formalised, systems from large corporations to national governments. (Sassen 2015)

As Sassen warns, the possibility of exercising and consolidating a "complexity in one's powerlessness" rests on the very possibility of a commons or domain maintained as diversely and fully 'public' - something we risk losing in the current appropriation of shared urban space and its over-determination formally, fiscally and socially.

The very incompleteness of the urban - as that which defines its most valuable and vulnerable version of cosmopolitanism - is similarly recognised by Richard Sennett (2010) in his deliberations on "The Open City". In the current closed mechanisms taking hold of urban space, he sees an escalating brittleness and inflexibility that does away with the deep redundancy and reusability of city fabric and the diverse cultural practices vested in it. Worse, within the neo-liberal rhetoric of 'freedom from constraint', is a quest to manipulate "closed bureaucratic systems for private gain by an elite” (Sennett 2010: 5). For Sennett, openness, by comparison, means finding in cities something like a liquid substance or "colloid" in which, suspended, the matter or physical substance of places interacts indeterminately and at times ambiguously with social behaviour (Sennett 2010: 6). In this sense definitive and fixed form, no less than normatively policed behaviours or desires, stand in the way of the densely diverse and disorderly dialogics necessarily voiced by cities when they presence the promise of city-ness. It is with precisely this sense of incompletion in mind that had us calling for an engagement with the idea of the urban as thing, a thing preceding object certainty and full knowing. We hoped to open up, in the context of an urban ubiquity that everywhere presses close, a distancing or problematicity in nomination as such. In short, how does the urban thing?

\section{Thinging}

Bill Brown, facing up to the difficult task of "thinking thingness" in the context of cultural theory and literary criticism, recognised a tendency already well in play from mid-century to relinquish theory in favour of a grappling with things (Brown 2004: 2). Where poets like Francis Ponge the 'poet of things' - might have found the prospect of dealing with ideas nauseating and things, by comparison, delightful (if not compelling in an abyssal sense) ${ }^{1}$, historicism, no less seduced by the substantive, longs for a "return of the 'real'”, while studies in material culture and art practices indexed to a reworking of the ordinariness of objects proliferate (Brown 2004: 2). Yet beginning with, or getting back to, things - things taken in their material certainty as objects - doesn't get around or on top of thingness; as Brown's unpacks, objects are what we see through untroubled by any opacity of sense, while things, far from windowing onto the expected, interrupt or breakdown causing us to wonder after them, and well... think (Brown 2004: 4). Thingness would be in this sense, what sits excessively in things, temporalised as Brown put it, "as the before and after of the object" except that this latency in fact subsists as an "all-atonceness", a simultaneity undoing even now-ness as a refuge (Brown 2004:
5). With Kant, thingness would side then with, but elude, "phenomenal form" thereby setting in play a long rehearsed release from the demand to think precisely there, while simultaneously impelling types of thinking (phenomenological, psychoanalytic, and more recently speculative realist) that potentially could (Brown 2004: 5-6). If the subject and its hold on the world is put centre-stage (or tactically pushed off-stage in the case of speculative realism) in this seesaw, things stand out as alienated entities (sometimes withdrawn, sometimes animated depending on cultural perspectives) uncannily persisting, in any case, aside, if not entirely apart, from human affairs (Brown 2004: 8).

Earlier still, Martin Heidegger in the essay “The Thing” recognised that the proliferation of actual things arising with industrialisation - commodities - and "the frantic abolition of all distance" associated with the circulatory mandate of urban life, in fact served to alienate us from things themselves (Heidegger 1975: 165). Further, while science might purport to get closest to "the real in reality", in fact the "thingness of the thing remains concealed, forgotten" (Heidegger 1975: 170). For as obliterating as the "atom bomb" is, as he noted, it is "only the grossest of all gross confirmations of the long-since-accomplished annihilation of the thing" (Heidegger 1975: 170). By reading into a modest object - a jug - the complex ways it holds open a space to gather or keep and give out or gift what is held (not just a liquid substance but an elemental associational nexus implicated with it) ${ }^{2}$, he argued that things reveal their thingness by standing out as conduits capable of drawing together into nearness an interconnectedness he called the fourfold "earth and sky, divinities and mortals" (Heidegger 1975: 173). In other words, thingness gathers or brings together an arena of common or public concern in which incommensurate, yet integral dimensions of the world commingle despite their difference remaining intact as distance (Heidegger 1975: 174-176). The thing-ness of a jug, say, is not in it per sewhich reduces the issue to matters of representation; in gathering it actions a "thinging" or bringing forth of a broader adjacency.

The urban too, might claim a jug-like summonsing of a void that holds and the gifting of outpour. Mumford has claimed as much in the context of the early Mesopotanian cities where irrigration channeling and the invention of pottery vessels were crucial to agricultural production and its stockpiling or storage permitting a dense and specialised peopling. ${ }^{3}$ Linked to maternal hollowing and veneration of a bountious earth, Mesopotanian clay tablets too became the first substance for recording inscrition and storing language - that mecahanism as Maurice Blanchot (1981) has written by which names murder things putting them within nominal grasp while casting things themselves into a shadowy domain beyond signification.

If key amongst Adam's sin at Eden was his transposing the world and its things into names (see Schwenger 2004: 138), his expulsion from the garden set in play a series of lapses, the most critical of which is access to a bountious earth and the need, for subsequent generations (from Enoch on), to secure sustenance by making cities. Urban life in this context would amount to a hollowed out place standing in for an absence of countanence as much as nourishment. Following Lacan's reading of the Heidegger's jugthing, while the potter could be said to craft a vessel around a hole that longs for and prompts filling (see Schwenger 2004: 147), the urban itself in its biblical conceiving might be understood as that which has been assembled about a lost object (a divine correlation) and the gathering it calls up a psychical mechanism for managing longing. Born of a departure seen through the eyes of "Israel's prophets", urban history can be thought to stage in the west a break with the oikoumene (or cosmic household as Jan Patočka has termed it; 1996: 35) and an Edenic series peculiar to the Judeo-Christian tradition, where "imbalance" and "eccentricity", in Michel Serres's account, engenders both an itinerant line and an aberrant course consequent to an alienation from a nutritive earth (Serres 1989: 10).

If Heidegger's calling up of a fourfold echoes this cultural-psychical 
disequilibrium and a broader project to recover in language an openness that withdraws, Bruno Latour building on Serres' history of science rejects Heidegger's mere fourfold in things, arguing instead that to think thingness in contemporary life it is necessary to engage with a thousandfold convening (Latour 2004: 160-161). As he puts it:

My point is thus very simple: things have become Things again, objects have reentered the arena, the Thing, in which they have to be gathered first in order to exist later as what stands apart. (Latour 2004: 161)

The arena he has in mind is that encircling of common or (human and non-human) public concern enveloping every phenomon; the fact of their standing rests on a gathering, a thinging, that adhers and insists manifestly so. Or put another way, as W. J. T. Mitchell does contra the errosive undermining of things Heidegger saw: "The slogan for our times then is, not things fall apart, but things come alive. The modernist anxiety over the collapse of structure is replaced by the panic over uncontrolled growth of structures - cancers, viruses, and other rapidly evolving entities" (232). A difficult to conceive, yet alone manage, material vitalism erupts across the scene. For Mitchell it is the legacy of a not yet finished romanticism that resonates in the plethora of appeals to things, materiality and physical objects, a resonance that confirms, as Latour has claimed, a not yet arrived modernity (244).

\section{In issue}

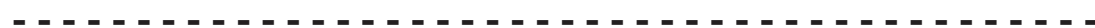

An invited paper by Mark Dorrian and Adrian Hawker titled "The exhibition as an urban thing'" takes up the question of whether thingness and the urban can be exhibited? Noting Bruno Latour's reworking of Martin Heidegger's essay “The thing”, Dorrian and Hawker similarly tease out a thing-object distinction seeing in Latour's contrasting of "matters of fact and concern" and its parallel demarcation between a will to master, in the case of objects, verses a tendency inherent in things to gather- the possibility that thingness potentiates both depending on how we chose to orientate to them. On the other hand, some things are more readily taken as things in the gathering sense, while others insistently draw us into object appreciation. Cities of course are both bundles of facts (or can be made so) no less than a convening (a parliament in fact to borrow Latour's sense) of concerns, as identified above. As a quasi-object, half animated and self-organising, half plastic substance 'man'-made, cities might also be seen as quasi-subjects, convening qualities in excess of persons as Musil had it. In Dorrian and Hawker's exposition of the exhibition On the Surface by Metis, at stake as they say, is a complex convening of retrieved things (a retrospective gathering of previous work) situated on, and in a certain sense within, a large floor drawing itself capturing multiple projects. The curatorial strategy worked to unsettle ground and scale drawing visitors into quasi-relations, relations undermining of the distancing that upholds objects.

Amongst the peer reviewed papers, Mark Jackson and Mark Hanlen diagnose an unsettling instability in modalities of planning and designing the future upon which government rationalities and design, as a predictive and derivative procedures, rely. Through a mapping of relations between space, power, contingency and writing, they critically trace the emergence of statistical and predictive modelling to better take hold of that erosive thing subsisting within all urban futures - risk. Robert Hughes paper questions forms of civic innovation, and by proxy politics, emerging from unmetered ambition for technocratic civic transformation. With an explication of the origins and organisational elements of NYC's selfappointment as the vanguard of a new global urban imaginary, the paper, speculates how Applied Sciences New York (ASNY) agitates and opens potential for new forms of citizen engagement. Hughes argues this new brand of digital urbanism, designed to be emulated by 'smart cities' the world over, reinvigorates the urban as a potential locus for open-ended 'world forming' resistance.

If the preceding two papers develop the socio-economic dimension of cities, Maria Koutsari, Elena Antonopoulou, and Christos Chondros in a paper titled "The urban creative factory: Creative ecosystems and (im) material design practices" further push into the consequences of postFordist work practices and an evolution towards immaterial production in the areas of information, knowledge, and affective, creative commerce. De-industrialised cities in the Global North, they argue, are subject to a radical makeover, one that sees them assume a factory-like organisation, but one recalibrated according to a biopolitical optimisation of productive capacity that takes up the entirety of living labour and commoditises via the production of ever-customised lifestyles and identities. Recognising the integral role of creative and design professions in this commodification, they ask what new worker categories and collectives might emerge in the creative urban factory and what emancipatory strategies and collaborations might exist for designers?

In the first of two papers that are broadly project-orientated, Simon Twose offers an exposition of his installation, Concrete Drawing exhibited at the Adam Art Gallery in a show titled "Drawing Is/Not Building", running April 24 - June 28, 2015. Drawn to think through material agency and certain economies of digital and analogue making, he unfolds the normative productive sequence that sees drawings lead to building, working instead from built work into drawings, that in turn engender further made objects. Arising via iterative design that foregrounds a variety of material engagements the work is shown to problematise objects, materials, scales and subjects in a parallel with built things and new designs for the city. In the second, Carola Moujan draw's the urban into question by asking can digitally augmented furniture support place-making practices now that digital informational devices, installed as things of the urban, are increasingly commonplace? Her critical commentary dispenses with technological performance to advocate the relational-orientated capacities of such devices as essentially aesthetic. Through the proposition of the notion of interspace [entr'espace] - experience of multiple dimensions coexisting within an integrated perception of realities- Moujan envisions augmentation as a form of polarisation of space through design that shifts from device, to spatial event.

The final two papers of the peer reviewed section take Tāmaki Makaurau /Auckland as subject. In the first, Andrew Douglas looks to the colonial founding of the town recognising in its formation a particularly poignant mixing of metropolitan and state imperatives or solutions aimed at heading off the systematic colonisation ambitioned by the New Zealand Company for Wellington and other colonial towns in the country. In a detailed reading of the largely unrealised 'Felton Mathew Plan' for Auckland, the paper seeks to contextualise the proposal relative to classical romantic European precedents and what can be thought of as lyric-epic sensibility transposed to the Tāmaki Isthmus - a sensibility it is argued that persists in an ongoing, topographically sensitised (sub)urbanism. Where Douglas' paper charts circumstances setting the city's founding, Manfredo Manfedini and Ross 
Jenner attend to the latest configurations of public expression in Tāmaki Makaurau /Auckland. Shopping centres they argue actualise emerging forms of urban public space particularly attuned to low-density cities within neo-liberal political frameworks. As integrated urban enclosures devoted to lifestyle consumption, they pointedly develop heterotopic qualities mobilised by spectacle in pursuit of a post-consumerist associative life apposite to the digital era.

Concluding the issue are two non-peer reviewed papers exploring projects indexed to situated urban encounter. In the first, Sophia Banou's drawing practice interrogates the material and temporal limits of conventional codes of architectural drawing to address the urban as a transitory condition within a gallery installed project. The work stages a dynamic representational field constituted by situated transcription of the city of Edinburgh, the actual city of Edinburgh, and the movement of spectators through the gallery. Banou asserts this trialectic confluence as a mode of inhabitation within the space of representation afford material recoding to emerge and persistently renegotiate between the city's actuality and its drawn image. In the second, Hannah Hopewell, locates the urban thing as a material thing of thought itself to engage an encounter with the notion of encounter at the urban intertidal space of Juhu Beach, Mumbai. Drawing from François Laruelle's non-standard thinking methods, the project labours inscriptive practices of photography, and philo-poetics to exemplify a mode of thought that presents things without being about them. Hopewell trials thingness to actualise an urban address that distresses the transcendent primacy of human gaze in urban diagnostic claims on identity, and thus makes space, not for a new mode of perception, but a radicalised 'experience of thought', which is to say, an experience of immanence.

Collectively, what these papers foreground is something of the open indeterminacy of urban relations and the spatial, fiscal and relational configurations upheld there. If the task of thinking the thingness of the urban has drawn out a certain inability of the phenomenological subject to put consciousness into all things as Musil had anticipated, the city without qualities might be seen less as a ubiquitous everyplace (what Marc Augé (2009) has termed a "non-place"), or as an empirical place given by 'the facts', but as a site of problematicity or concern opening the experience of thought. If the question of a thinging of the urban turns on its substantiveness, its ontological configuring, Musil's world "of qualities without a man" suggests, not a place where "being = is" (Flaxman 2000: 47), but one engendered - for better or worse - immanently. 


\section{Endnotes}

\section{- - - - - - - -}

1 Scrutinising what is near to hand, Ponge wrote, means attending to its singleness, a singleness what tends to gape inordinately, becoming, as he said, a precipice of associations. For instance, in the poem "The Pebble" he concluded: "Only too happy to have chosen for these beginnings the pebble: for a man of wit cannot fail to be amused, and also moved, when my critics say: 'Having undertaken to write a description of stone, he got buried under it'” (Ponge 1972: 77).

2 For example: "The giving of the outpouring can be a drink. The outpouring gives water, it gives wine to drink. The spring stays on in the water of the gift. In the spring the rock dwells, and in the rock dwells the dark slumber of the earth, which receives the rain and dew of the sky. In the water of the spring dwells the marriage of sky and earth" (Heidegger 1975: 172).

As Mumford put it: “Under woman's dominance, the Neolithic period is pre-eminently one of containers: it is an age of stone and pottery utensils, of vases, jars, vats, cisterns, bins, barns, granaries, houses, not least great collective containers, like irrigation ditches and villages [...] It was in permanent containers that Neolithic invention outshone all earlier cultures" (Mumford 1984: 25). 


\section{References}

Appadurai, A. and Holston, J. (2003). Cities and citizenship. In N. Brenner, B.Jessop, M.Jones, G. MacLeod (Eds.), State/space: A reader (pp. 296-308). Malden, MA: Blackwell. Augé, M. (2009). Non-places: An Introduction to supermodernity (J. How, Trans.). London, England and New York, NY: Verso.

Blanchot, M., Adams Sitney, P. (Ed.), (1981). 'The gaze of Orpheus' and other literary essays (L. Davis, Trans.). Barrytown, NY: Station Hill Press.

Brown, B. (2004). Thing theory. In Brown, B. (Ed.), Things (pp. 1-22). Chicago, Ill \& London, England: The University of Chicago Press.

Flaxman, G. (2000). Introduction. In G. Flaxman (Ed.), The brain is the screen: Deleuze and the philosophy of cinema. Minneapolis, MN and London, England: University of Minnesota Press.

Latour, B. (2004). Why has critique run out of steam? From matters of fact to matters of concern. In Brown, B. (Ed.), Things (pp. 151-173). Chicago, Ill \& London, England: The University of Chicago Press.

Mitchell, W. J. T., (2004). Romanticism and life of things: Fossils, totems, and images. In, Brown, B. (Ed.), Things (pp. 151-173). Chicago, Ill \& London, England: The University of Chicago Press.

Mumford, L. (1984). The city in history. Harmondsworth, Middlesex, England: Penguin Books.

Musil, R. (1996). The man without qualities. New York, NY: Vintage International.

Nancy, J.-L. (2007). Urbis et Orbi (F. Raffoul \& D. Pettigrew, Trans.). In, The creation of the world or globalization (pp. 31-56). New York, NY: Suny Press.

Patočka, J., \& Dodd, J. (1996). Heretical essays in the philosophy of history (E. Kohák, Trans.). Chicago \& La Salle, IL: Open Court.

Ponge, F., Archer, B. (Ed.), (1972). The voice of things (B. Archer, Trans.). New York, NY: McGraw-Hill.

Schwenger, P. (2004). Words and the murder of the thing. In Brown, B. (Ed.), Things (pp. 135-149). Chicago, Ill \& London, England: The University of Chicago Press.

Sassen, S. (2014). Expulsions: Brutality and complexity in the Global Economy. Cambridge, MA \& London, England: Harvard University Press.

Sassen, S.(2015 ,Tuesday 24 November). Who owns our cities - and why this urban takeover should concern us all. Guardian. Retrieved from http://www.theguardian.com/ cities/2015/nov/24/who-owns-our-cities-and-why-this-urban-takeover-should-concern-us-all

Sennett, R. (2006, November). The open city. Urban age. Berlin. Retrieved from http://downloads.lsecities.net/0_downloads/Berlin_Richard_Sennett_2006-The_Open_City.pdf Sennett, R. (2010). The Public Realm. In Gary Bridge and Sophie Watson (eds.), The Blackwell City Reader, (pp. 261-272). London: Blackwell.

Serres, M. (1989). Detachment (G. James \& R. Federman, Trans.). Athens: Ohio University Press. 